\title{
BMJ Open Real-life evaluation of European and American high-risk strategies for primary prevention of cardiovascular disease in patients with first myocardial infarction
}

\author{
Martin B Mortensen, Erling Falk
}

To cite: Mortensen MB, Falk E. Real-life evaluation of European and American highrisk strategies for primary prevention of cardiovascular disease in patients with first myocardial infarction. BMJ Open 2014;4:e005991. doi:10.1136/bmjopen-2014005991

- Prepublication history and additional material is available. To view please visit the journal (http://dx.doi.org/ 10.1136/bmjopen-2014005991).

Received 27 June 2014 Revised 15 August 2014 Accepted 16 September 2014

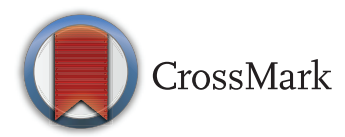

Atherosclerosis Research Unit, Department of Cardiology, Aarhus University Hospital, Aarhus, Denmark

Correspondence to Dr Martin B Mortensen; Martin.bodtker.mortensen@ ki.au.dk

\section{ABSTRACT}

Objective: To determine the detection rate (sensitivity) of the high-risk strategy recommended in the European Society of Cardiology (ESC) and National Institute for Health and Care Excellence (NICE/UK) and American College of Cardiology/American Heart Association (ACC/AHA) guidelines on cardiovascular disease (CVD) prevention. In particular, to evaluate the ability to ensure statin therapy to contemporary Europeans destined for a first myocardial infarction (MI).

Design: 393 consecutive statin-naïve, CVD-free patients without diabetes hospitalised for a first MI, 247 of whom were 40-75 years of age. We assumed they had undergone a health check the day before their MI and estimated the predicted risk.

Primary outcome: Sensitivity of the risk-based eligibility for primary prevention with statins recommended by the guidelines.

Results: All recommended risk scores rank-ordered patients similarly, but the sensitivity of the cut point above which statin therapy should be considered differed substantially. In younger patients (age $40-60$ ), $62 \%$ of men and $13 \%$ of women qualified for statin therapy by ACC/AHA criteria, compared with only $2 \%$ of men and no women using the ESC criteria recommended for most non-Eastern European countries. In those 60-75 years of age, the ACC/AHA guidelines captured all men and $85 \%$ of women, compared with $12 \%$ and $2 \%$, respectively, using the new ESC guideline. This guideline restricted the eligibility for primary prevention with statins substantially by reclassifying many European countries from 'high-risk' to 'low-risk', whereas the eligibility was expanded in the ACC/AHA and the new NICE/UK guidelines by lowering the decision threshold.

Conclusions: The 2012 ESC guidelines differ substantially from the 2013 ACC/AHA and 2014 NICE/ UK guidelines in ability to secure statin therapy to those destined for a first MI. A great opportunity for primary prevention with statins remains unexploited in Europe.

\section{Strengths and limitations of this study}

Cohort of consecutive, contemporary patients hospitalised with a first myocardial infarction (MI), representing those seen in clinical practice today.

- Estimation of the detection rate (sensitivity) of a high-risk strategy to prevent MI in a representative cohort of contemporary patients without diabetes with failed prevention (first MI).

- A 'reality check' of a high-risk strategy in contemporary patients with failed prevention is easy to perform world-wide, inexpensive, and provides useful information rapidly.

- Only the detection rate (sensitivity), not the specificity, can be determined by focusing only on those who develop cardiovascular disease.

\section{INTRODUCTION}

The guidelines on cardiovascular disease (CVD) prevention were revised recently in Europe and the USA. ${ }^{1-4}$ In 2012, the European Society of Cardiology (ESC) continued to stress the importance of using a well-calibrated version of the mortality-based SCORE (Systematic COronary Risk Evaluation) algorithm in the primary prevention of CVD. Consequently, because of secular trends of declining CVD mortality, many European countries were reclassified from 'high-risk' to 'low-risk' and recommended to use the SCORE low-risk algorithm instead of the high-risk algorithm. The age-dependent risk thresholds above which primary prevention with statins should be considered were preserved. In 2013, the American College of Cardiology and the American Heart Association (ACC/AHA) released new guidelines ${ }^{23}$ in which a risk calculator based on new risk equations (pooled cohort equations, PCE) was introduced, 
together with new risk-dependent thresholds above which primary prevention with statins should be considered. In 2014, the National Institute for Health and Care Excellence (NICE) in the UK recommended to halve the risk-based threshold for primary prevention with statins based on QRISK, ${ }^{4}$ endorsed by the third Joint British Societies' (JBS3) consensus recommendations for the prevention of CVD. ${ }^{5}$ Thus, in current European and American guidelines, different criteria are used to identify people in need for primary prevention with statins.

These guidelines are endorsing the paradigm of matching the intensity of risk-reducing therapy to the absolute 10-year risk of the patient. ${ }^{1-4}$ Although it takes many years of follow-up to evaluate how accurate the recommended risk equations (SCORE, PCE and QRISK) are calibrated, their ability to rank-order people by predicted risk and ensuring statin therapy to those at highest risk can be evaluated and compared in contemporary patients with a first CVD event. We did such a 'reality check' of the new guidelines and those they replaced in patients hospitalised for a first myocardial infarction (MI).

\section{METHODS}

\section{Study population}

We reviewed the medical records of 605 consecutive patients admitted to three hospitals in Denmark (departments of cardiology/medicine at Aarhus University Hospital and the Regional Hospitals in Herning and Randers) with a first acute MI between 1 January and 31 December in 2011. The universal definition of MI is implemented in Denmark, ${ }^{6}$ and the patients were identified via hospital registers using International Classification of Diseases 10 (ICD-10) codes I21.0 through I21.9. Patients with pre-existing CVD $(n=48)$, diabetes $(n=92)$, incomplete risk factor information $(n=32)$ and statin users $(n=40)$ were excluded (patients with diabetes do not belong to the target population for risk assessment defined by the ESC and ATP III guidelines), leaving 393 statin-naive, CVD-free patients without diabetes with first MI. To match the age range used in the ACC/AHA guideline, we limited the study population to those $40-75$ years of age $(n=247 ; 162$ men and 85 women). We extracted information on traditional risk factors (age, sex, smoking status, total cholesterol, high-density lipoprotein (HDL) cholesterol and systolic blood pressure) as previously described. ${ }^{7}$ Plasma cholesterol was measured early after admission (within the first $24 \mathrm{~h}$ ), and available pre-MI values were used to assess possible changes related to the acute phase of MI. The blood pressure used for estimation of risk was measured in a stable phase, either before MI (previous hospitalisation or general practitioner) or after recovery from the acute phase (just before hospital discharge or first visit to the rehabilitation clinic).

\section{Estimation of predicted risk and eligibility for statin}

The guideline-recommended risk equations and web calculators used to determine predicted risk, risk factors (predictors), clinical end points, definitions of high-risk and recommended decision thresholds above which statin therapy should be considered are shown in table 1 and described in the online appendix.

\section{Comparison of CVD prevention guidelines}

We evaluated and compared the performance of the American and European primary prevention guidelines shown in table 1. For each patient we calculated the absolute 10-year risk for the predicted outcomes using the recommended risk equations or calculators. In accordance with the SCORE risk charts ${ }^{1}$ and the online risk calculator HeartScore, ${ }^{17}$ the age-dependent risk was

Table 1 Guidelines and risk equations used to estimate 10-year risk for a first cardiovascular event (primary prevention)

\begin{tabular}{|c|c|c|c|c|}
\hline \multirow{2}{*}{$\begin{array}{l}\text { Guideline } \\
\text { Risk equation }\end{array}$} & \multicolumn{2}{|l|}{ Derivation cohorts } & \multirow{2}{*}{$\begin{array}{l}\text { Eligibility for statin } \\
\text { therapy } \dagger\end{array}$} & \multirow[b]{2}{*}{ Predicted outcomes } \\
\hline & Baseline examination ${ }^{\star}$ & Age range & & \\
\hline $\begin{array}{l}2012 \mathrm{ESC}^{1} \\
\text { SCORE }\end{array}$ & $\begin{array}{l}\text { Europe }^{10} \\
1967-1986\end{array}$ & $19-80$ & $\begin{array}{l}\geq 5 \%(\text { age } \leq 60) \\
\geq 10 \%(\text { age } 60-65)\end{array}$ & $\begin{array}{l}\text { Fatal ASCVD: } \\
\text { CHD, stroke etc }\end{array}$ \\
\hline $\begin{array}{l}2013 \mathrm{ACC} / \mathrm{AHA}^{3} \\
\text { Pooled Cohort } \\
\text { Equations (PCE) }\end{array}$ & $\begin{array}{l}\text { FHS: } 1948^{1112} \\
\text { CARDIA: } 1985^{13} \\
\text { ARIC: } 1986^{14} \\
\text { CHS: } 1989^{15}\end{array}$ & $\begin{array}{l}\text { FHS: } 30-59 \\
\text { CARDIA: } 18-30 \\
\text { ARIC: } 35-74 \\
\text { CHS: } \geq 65\end{array}$ & $\begin{array}{l}\geq 7.5 \% \\
\text { (strong/class I) } \\
5 \% \text { to }<7.5 \% \\
\text { (weak/class Ila) }\end{array}$ & $\begin{array}{l}\text { ASCVD: } \\
\text { non-fatal MI, fatal CHD, } \\
\text { fatal and nonfatal stroke }\end{array}$ \\
\hline $\begin{array}{l}\text { NCEP-ATP } \| I^{89} \\
\text { ATP III }\end{array}$ & $\begin{array}{l}\text { Framingham } \\
1971^{8}\end{array}$ & $30-74$ & $\begin{array}{l}20 \% \text { ( unconditional) } \\
10 \% \text { (conditional) }\end{array}$ & $\begin{array}{l}\text { Hard CHD: } \\
\text { non-fatal MI, fatal CHD }\end{array}$ \\
\hline $\begin{array}{l}2014 \mathrm{NICE}^{4} \\
\text { QRISK2-2013 }\end{array}$ & $\begin{array}{l}\text { UK: } 1993^{16} \\
\text { (updated annually) }\end{array}$ & $35-74$ & $\geq 10 \%$ & $\begin{array}{l}\text { Fatal and non-fatal CVD: } \\
\text { CHD (+angina), stroke, TIA }\end{array}$ \\
\hline
\end{tabular}


Table 2 Baseline characteristics of study population

\begin{tabular}{llll}
\hline Characteristics & All (40-75 years) & $\mathbf{4 0 - 6 0}$ years & $\mathbf{6 1 - 7 5}$ years \\
\hline Patients no & 247 & $96(39 \%)$ & $151(61 \%)$ \\
Age & $61.9(9.3)$ & $51.7(4.9)$ & $68.4(4.2)$ \\
Men & $162(66 \%)$ & $65(68 \%)$ & $97(64 \%)$ \\
Systolic blood pressure, mm Hg & $137(19.8)$ & $131(19.0)$ & $140(21.4)$ \\
Plasma parameters, median (IQR) & & & $5.4(1.0)$ \\
$\quad$ Total cholesterol, mmol/L & $5.3(1.0)$ & $3.4(0.9)$ & $3.3(0.9)$ \\
$\quad$ LDL cholesterol, mmol/L & $3.3(0.9)$ & $1.2(0.4)$ & $1.3(0.4)$ \\
HDL cholesterol, mmol/L & $1.3(0.4)$ & 63 & 38 \\
Current smokers, \% & 53 & 21 & 35 \\
Blood pressure lowering therapy, \% & 30 & & \\
\hline Continuous variables: mean (SD). & & \\
HDL, high-density lipoprotein; LDL, low-density lipoprotein. & &
\end{tabular}

capped at age 65 when estimating risk using the SCORE algorithms. The guidelines were compared in three steps as described in the online appendix.

\section{RESULTS}

Baseline characteristics of the study population are shown in table 2. We identified 393 statin-naïve, CVD-free patients without diabetes with first MI of whom 13 below age 40 and 133 above age 75 were excluded, leaving 247 patients (162 men, 85 women) for the present study.

\section{ACC/AHA versus ATP III}

Ranking patients with first MI by predicted risk estimated by PCE (used in the new ACC/AHA risk calculator) and the previously recommended ATP III risk calculator correlated strongly (figure 1). PCE risk $\geq 7.5 \%$, which is a strong/class I recommendation for statin therapy, corresponded to ATP III risk $\geq 9.5 \%$ in men and $\geq 4.1 \%$ in women and, compared with ATP III risk $\geq 10 \%$, captured nearly the same men but substantially more women with first MI (figures 1 and 2, table 3).

\section{ACC/AHA versus 2014 NICE/UK}

Ranking patients with first MI by predicted risk estimated by PCE and the QRISK risk calculator correlated strongly (figure 3). A PCE risk of $7.5 \%$ corresponded to a risk of $7 \%$ in men and $10.1 \%$ in women estimated by QRISK (table 3). Thus, with the 2014 NICE/UK recommendation to lower the QRISK-based threshold for statin therapy from $20 \%$ to $10 \%$, the eligibility for primary prevention with statins is nearly similar in the USA and the UK (figures 2 and 3).

\section{ACC/AHA versus 2012 ESC}

Ranking patients with first MI by predicted risk estimated by PCE and SCORE+HDL high-risk equations correlated
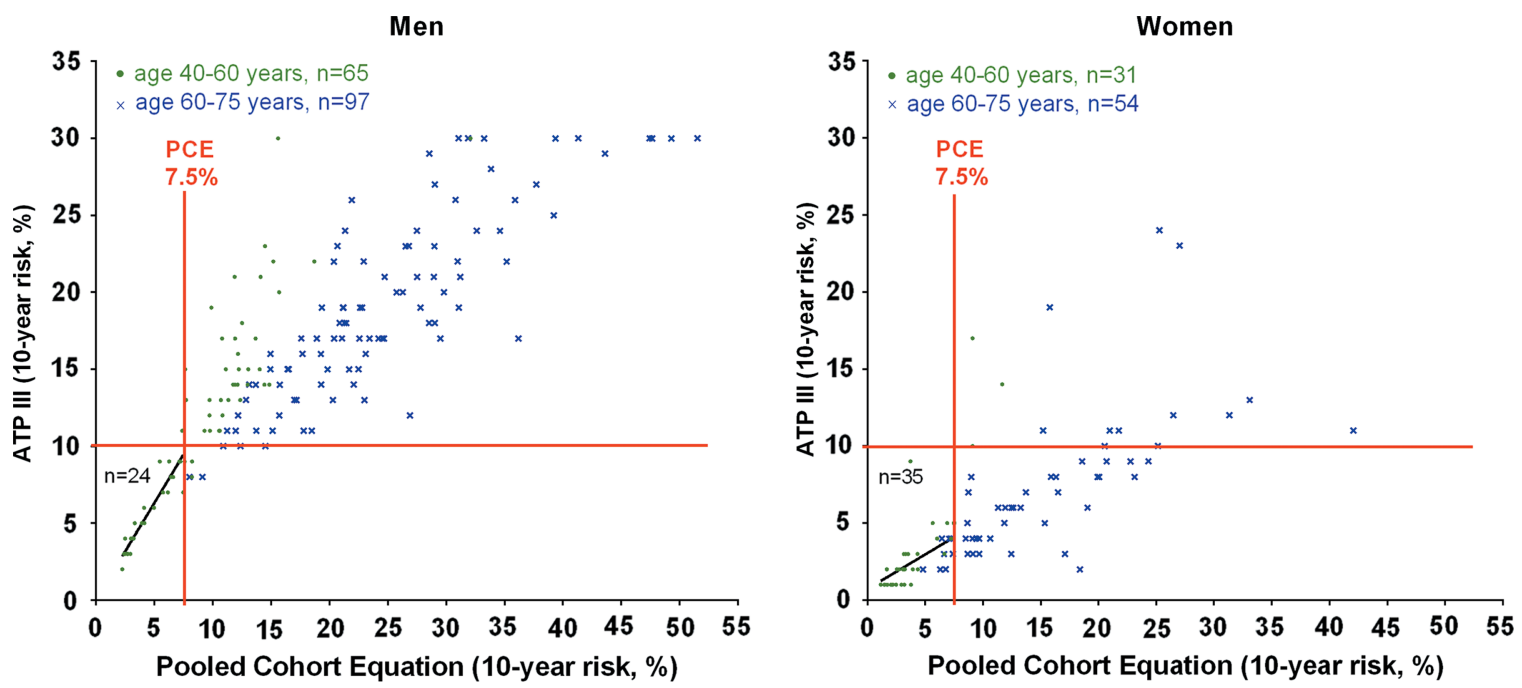

Figure 1 Eligibility for statin therapy by ACC/AHA versus adult treatment panel (ATP III). Predicted risk estimated by the pooled cohort equations (PCE) and the ATP III risk calculator correlated strongly (Spearman's $r 0.86$ in men and 0.82 in women; $\mathrm{p}<0.0001$ ). Compared with ATP III risk $\geq 10 \%$, PCE risk $\geq 7.5 \%$ captured nearly the same men but substantially more women with first myocardial infarction. The ATP III risk calculator only provides whole numbers, and the absolute risk is capped at $30 \%$. For $P C E<7.5 \%, y=1.261^{*} x+0.00026$ in men, and $y=0.4476^{*} x+0.7274$ in women. 
Figure 2 Proportion (\%) of patients with first myocardial infarction who would have been eligible for primary prevention with statins. The SCORE low-risk equation is recommended for use in Denmark and 24 other European countries with a relatively low cardiovascular mortality. The exact values and guideline-defined decision thresholds behind this bar diagram are shown in the online appendix (see online supplementary table).

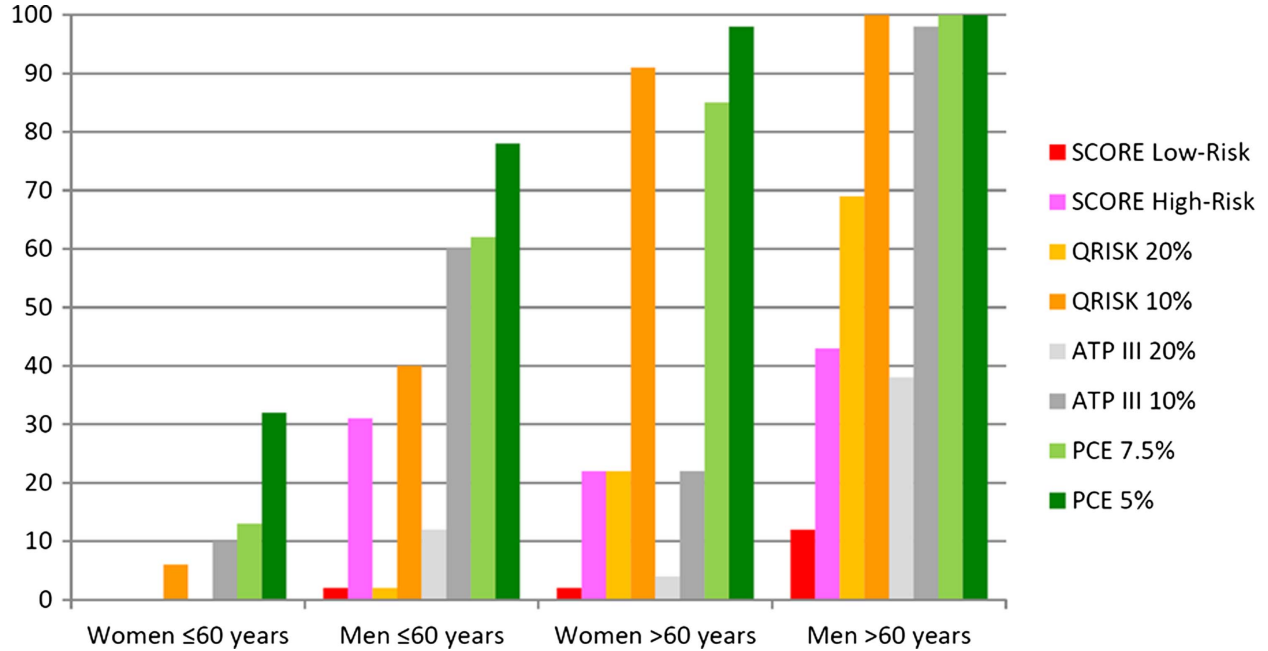

strongly (figure 4). A PCE risk of $7.5 \%$ corresponded to a risk of $2.9 \%$ in men and $3.6 \%$ in women estimated by the SCORE+HDL high-risk equation (table 3).

The 2013 ACC/AHA guideline captured double as many men and four times more women with first MI compared with a common interpretation of the 2012 ESC guideline (SCORE $\geq 5 \%$ below age 60 and $\geq 10 \%$ above 60 ; figures 2 and 4 ). This contrasting performance was accentuated with the SCORE low-risk equation recommended for use in Denmark and most other non-Eastern European countries (figure 5). PCE $7.5 \%$ corresponded to SCORE $1.5 \%$ in men and $2 \%$ in women (table 3 ). Below age 60 , only $2 \%$ of men and no women with first MI qualified for statin therapy by the ESC guideline (SCORE $\geq 5 \%$ ), whereas $62 \%$ of men and $13 \%$ of women qualified for a class I recommendation by the ACC/AHA guideline (figure 2 ). Above age $60,12 \%$ of men and $2 \%$ of women qualified for treatment in Europe (SCORE $\geq 10 \%$ ), in contrast to all men and $85 \%$ of women in the USA.

\section{ESC 2012 versus ESC 2003 and 2007}

Predicted risk estimated by the SCORE+HDL high-risk and low-risk equations correlated perfectly (see online supplementary figure). Predicted risk was 1.7 times

Table 3 Risk equivalent to PCE 7.5\% and 5\% determined by other risk equations*

\begin{tabular}{|c|c|c|c|c|c|}
\hline & \multicolumn{5}{|c|}{$\begin{array}{l}\text { Predicted 10-year risk of diverse CVD } \\
\text { outcomes }(\%)\end{array}$} \\
\hline & $\begin{array}{l}\text { PCE } \\
2013\end{array}$ & $\begin{array}{l}\text { ATP } \\
\text { III } \\
2002 \\
\end{array}$ & $\begin{array}{l}\text { QRISK2 } \\
2013\end{array}$ & $\begin{array}{l}\text { SCORE } \\
+ \text { HDL } \\
\text { High-Risk }\end{array}$ & $\begin{array}{l}\text { SCORE } \\
+ \text { HDL } \\
\text { Low-Risk } \\
\end{array}$ \\
\hline \multirow[t]{2}{*}{ Men } & 7.5 & 9.5 & 7.0 & 2.9 & 1.5 \\
\hline & 5 & 6.3 & 5.4 & 2.1 & 1.1 \\
\hline \multirow[t]{2}{*}{ Women } & 7.5 & 4.1 & 10.1 & 3.6 & 2.0 \\
\hline & 5 & 3.0 & 6.8 & 2.1 & 1.2 \\
\hline
\end{tabular}

*Based on linear regression of those with PCE risk $<7.5 \%$ (figures 1 and 3-5).

ATP III, Adult Treatment Panel III; CVD, cardiovascular disease; HDL, high-density lipoprotein; PCE, pooled cohort equations; SCORE, Systematic COronary Risk Evaluation. higher in men and 1.9 times higher in women when estimated by the high-risk equation compared with the low-risk equation. Thus, $5 \%$ risk determined by the highrisk equation recommended until 2012 corresponded to only $2.9 \%$ risk in men and $2.6 \%$ risk in women determined by the low-risk equation now recommended. Consequently, 85 of 162 males (52\%) and 27 of 85 females $(32 \%)$ with a first MI who would have been eligible for primary prevention with statins under the previous ESC guidelines lost their eligibility when Denmark (and many other European countries) was reclassified from a 'high-risk' to a 'low-risk' country in the new guidelines (figure 2 and online supplementary figure). ${ }^{1}$

\section{DISCUSSION}

A 'reality check' of guidelines on CVD prevention in patients with a first MI revealed that many more patients would have been eligible for primary prevention with statins by following the 2013 ACC/AHA and 2014 NICE/UK guidelines compared with the 2012 ESC guideline. The use of statins was liberalised in the USA in 2013 and the UK in 2014, but indirectly restricted in many European countries in 2012 by recommending the SCORE low-risk equation instead of the high-risk equation. ${ }^{1}$ With the low-risk equation, only 13 of 162 men $(8 \%)$ and 1 of 85 women (1\%) with a first MI would have qualified for primary prevention with statins, leaving ESC alone with increasingly restrictive recommendations on primary prevention with statins.

As expected, ranking patients by predicted risk estimated with different multifactorial risk equations correlated strongly, and previous studies have shown that their ability to discriminate cases from non-cases is similar for practical purposes. ${ }^{18} 19$ Thus, the clinical performance depends critically on how accurate risk is estimated (calibration) and the decision thresholds recommended in the respective guidelines.

\section{US guideline}

With the release of the 2013 ACC/AHA guideline, a new risk calculator based on PCE was introduced. ${ }^{3}$ We were 

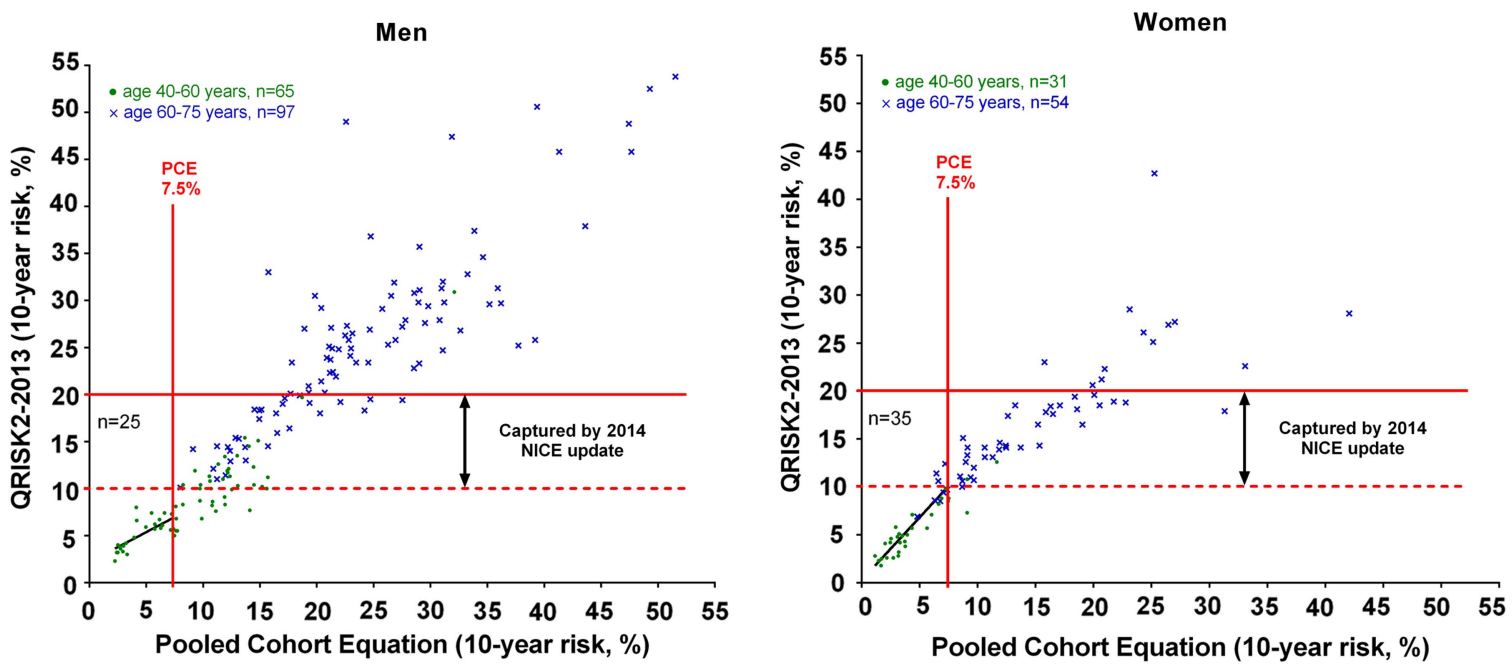

Figure 3 Eligibility for statin therapy by ACC/AHA versus NICE/UK. Predicted risk estimated by the pooled cohort equations (PCE) and the QRISK2-2013 risk equation correlated strongly (Spearman's $r 0.94$ in men and 0.97 in women; $p<0.0001$ ). Compared with PCE risk $\geq 7.5 \%$, QRISK $\geq 20 \%$ (indication for statin therapy in the previous NICE guideline) identified much fewer patients with first myocardial infarction, whereas QRISK $\geq 10 \%$ (indication for statins in the 2014 NICE update) identified nearly the same patients, especially among women. For PCE $<7.5 \%, y=0.6385^{\star} x+2.171$ in men, and $y=1.308^{\star} x+0.2708$ in women.

not able to access calibration of PCE in our study population, but recent data indicates that PCE is reasonable well calibrated (similar to SCORE) in a UK 'low-risk' population. $^{20}$ This observation provides a reasonable background for comparing PCE directly with SCORE and QRISK in a European country classified as 'low-risk' (figures 3 and 5).

We estimated and compared predicted risk and found that a PCE risk of $7.5 \%$ corresponded to an ATPIII risk of $\sim 10 \%$ in men and $\sim 4 \%$ in women (figure 1 and table 3 ), documenting that the bar for primary prevention with statin therapy deliberately was lowered by the 2013 ACC/
AHA guideline, especially in women. ${ }^{21}{ }^{22}$ Concerns have been raised about the potential risk of overtreatment. ${ }^{23}$ In patients with first MI who were 60-75 years of age, the sensitivity of the new class I recommendation for statin therapy (PCE $\geq 7.5 \%$ ) was $100 \%$ in men and $85 \%$ in women (figure 2). The new cut point for treatment was established based on risk-benefit considerations alone, ${ }^{2} 3$ cost-effectiveness of fixed-dose not target driven statin therapy was not questioned. ${ }^{22}$ A recent review concluded that the new recommendations for statin therapy 'generally meet societal acceptable levels of cost-effectiveness' . 24 The ACC/AHA guidelines are expected to increase the
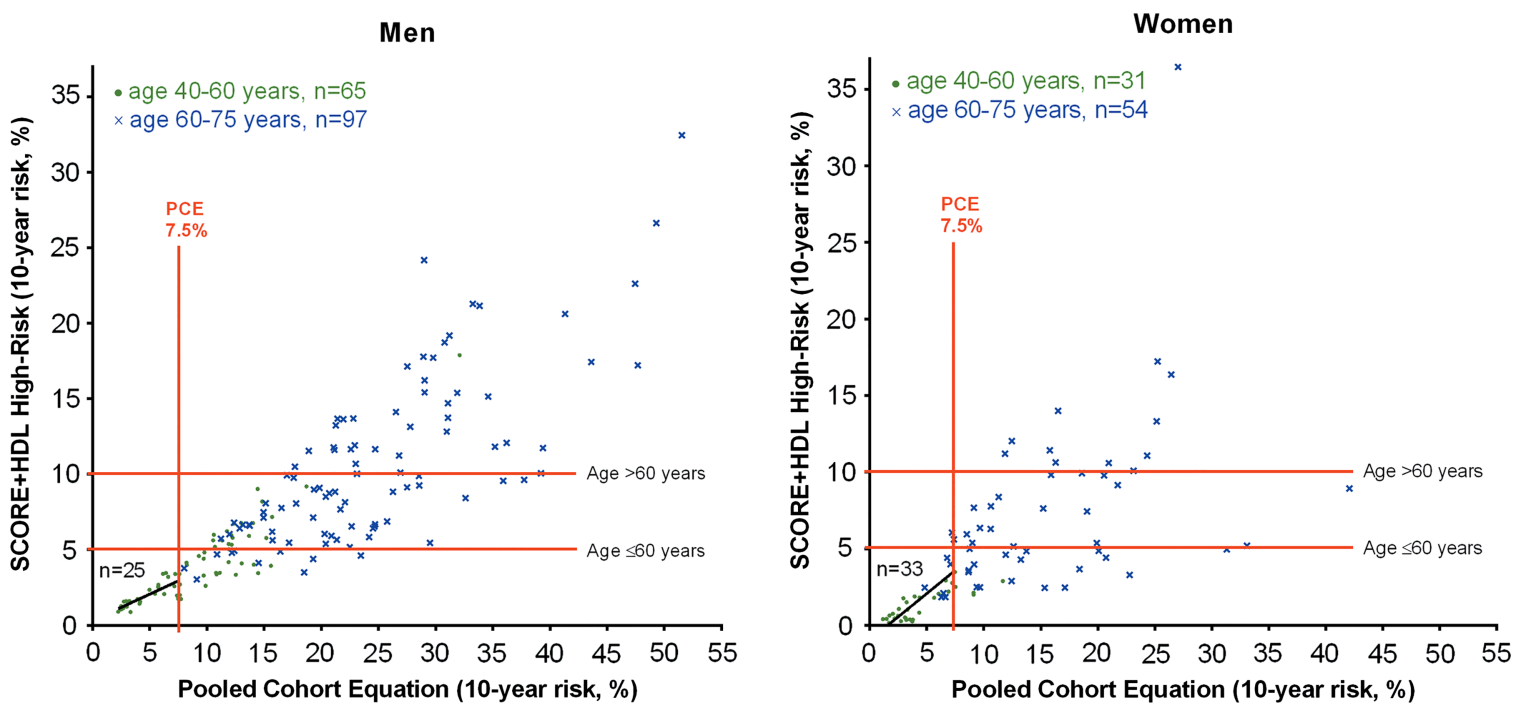

Figure 4 Eligibility for statin therapy by ACC/AHA versus ESC 'high-risk' countries. Predicted risk estimated by the pooled cohort equations (PCE) and the SCORE+HDL high-risk equation correlated strongly (Spearman's r 0.89 in men and 0.84 in women; $\mathrm{p}<0.0001$ ). The PCE-defined treatment threshold of $7.5 \%$ captured double as many men and four times more women with first myocardial infarction compared with the SCORE-defined treatment thresholds of $5 \%$ below age 60 and $10 \%$ above 60 . For PCE $<7.5 \%, y=0.3514^{*} x+0.3034$ in men, and $y=0.6065^{*} x+0.9550$ in women. 

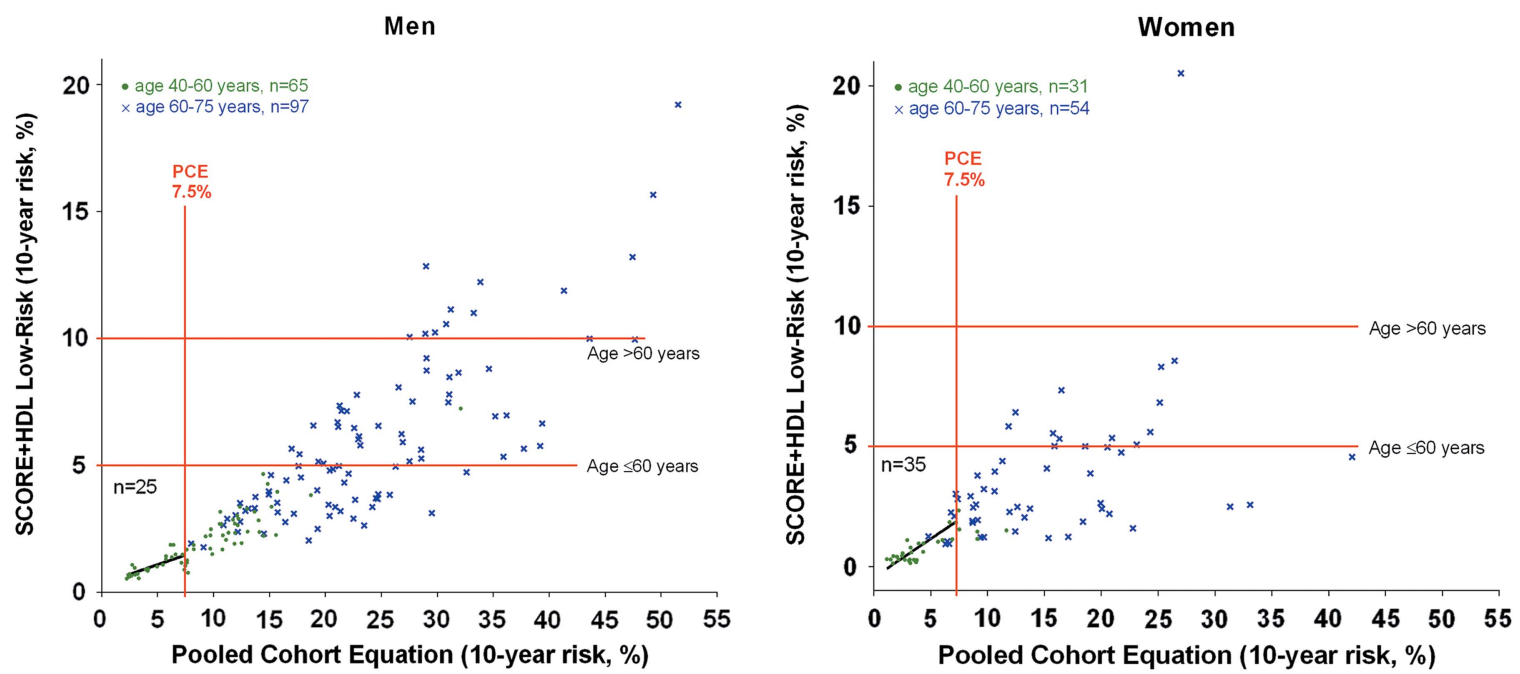

Figure 5 Eligibility for statin therapy by ACC/AHA versus ESC 'low-risk' countries. Predicted risk estimated by the pooled cohort equations (PCE) and SCORE+HDL low-risk equation correlated strongly (Spearman's r 0.91 in men and 0.83 in women; $p<0.0001)$. Only 13 of 162 men $(8 \%)$ and 1 of 85 women $(1 \%)$ with first myocardial infarction qualified for primary prevention with statins using the SCORE-defined treatment threshold of $5 \%$ below age 60 and $10 \%$ above 60 . For PCE $<7.5 \%, y=0.1519^{*} x$ +0.3258 in men, and $y=0.3203^{*} x-0.4519$ in women.

number of people eligible for primary prevention with statins in the USA substantially. ${ }^{25}$

\section{European guidelines}

The SCORE-based ESC guidelines have always stressed that the indication for drug therapy should be based on an accurate estimate of absolute risk for fatal CVD, taking age into consideration. ${ }^{1} \mathrm{~A}$ paradoxical consequence is that when SCORE is recalibrated to fit a lower CVD mortality, it becomes harder to get the treatment that contributed to the lower mortality. Thus, the 2012 ESC guideline indirectly restricted the use of risk-reducing statins by reclassifying many high-income European countries from 'high-risk' to 'low-risk' and recommending the more accurately calibrated SCORE low-risk equations instead of the high-risk equations. ${ }^{1}$ Twenty-five European countries are now classified as 'low-risk', compared with only eight in $2007 .{ }^{1}$ With preserved age-dependent and risk-dependent eligibility for statin therapy, our data show that the low-risk equations capture very few people destined for a first MI (figure 2). Obviously, the current mortality-based decision thresholds are not geared to prevent the large burden of non-fatal CVD and still increasing healthcare costs.

QRISK predicts an expanded CVD end point compared with PCE (PCE end points+angina and transient ischaemic attack) and, consequently, risks estimated by the QRISK2-2013 risk calculator should be higher than those estimated by the PCE-based risk calculator. Nonetheless, they do not differ much (figure 3 and table 3), which indicates that at least one of these risk models is miscalibrated in contemporary patients. However, the recent lowering of the treatment threshold from QRISK $20 \%$ to $10 \%{ }^{4}$ brings the guideline in UK close to the 2013 ACC/AHA guideline.

\section{Contrasting recommendations after age $\mathbf{6 0}$}

The 2013 ACC/AHA guideline recommends neither for nor against statin therapy for primary prevention in people without diabetes above $75 .^{3}$ The 2014 NICE guideline recommends to use the same risk-based indication for primary prevention with statins up to age $85 .{ }^{4}$ In older people, the new recommendation 55 reads as follows; 'For people 85 years or older consider atorvastatin $20 \mathrm{mg}$ as statins may be of benefit in reducing the risk of non-fatal myocardial infarction. Be aware of factors that may make treatment inappropriate (see recommendation 48)'. ${ }^{4}$ In contrast, the ESC guideline recommends a higher bar for statin treatment already after age 60 and provides SCORE risk charts only up to age $65 .{ }^{1}$ Beyond age 65 , the ESC guidelines provide no guidance on how to assess risk. It is possible, but not recommended, to enter age up to 100 years in the online risk calculator, HeartScore, but the age-dependent risk is capped at age $65 .{ }^{17}$ So, in clinical practice, very few elderly people in 'low-risk' countries will qualify for primary prevention with statins if the ESC guidelines are used as intended. In an elderly European population, a high eligibility for statin therapy was recently reported by calculating the risk by entering the actual age into the underlying SCORE equations and thus ignoring how SCORE is used clinically where the age-dependent risk is capped at age $65 .{ }^{26}$

\section{Limitations of the traditional high-risk strategy based on prospective cohort studies}

When treatment decisions are based on absolute 10-year risk for developing CVD, accurate estimation of 10-year risk is essential to treat people as intended. ${ }^{27}$ It is problematic for several reasons. Predicting risk based on historical and potentially outdated data is risky in 
populations where lifestyle, medicalisation, morbidity and mortality are changing rapidly. ${ }^{21} 232829$ A contemporary (sub) population against which to update (recalibrate) a risk score is often lacking. ${ }^{18} 21$ Applicable 'natural history' cohorts are vanishing because of wider use of risk-reducing medications already at baseline and during follow-up. ${ }^{21} 30$ Generalisability may be questioned because of selection bias, ${ }^{21}$ non-reproducible or inapplicable end points or uncertain ascertainment and adjudication. $^{2} 1030$ Overall, a primary prevention strategy based on absolute risk is not always feasible, illustrated by the suboptimal guidance to ethnic groups other than non-Hispanic Whites and African-Americans in the new ACC/AHA guidelines. ${ }^{2} 3$

Our study illustrates that important complementary information may be provided by a simple 'really check' in contemporary patients with a first MI, revealing an extraordinarily low sensitivity of the guideline-defined threshold for intensified prevention in a European 'low-risk' country. ${ }^{1}$ Such a reality check is easy to perform world-wide, inexpensive and provides useful information rapidly. To put it into perspective, our reality check included 247 patients hospitalised with a first MI, in the JUPITER trial only 62 non-fatal MI were observed among 8901 placebo patients during nearly 2 years of follow-up. ${ }^{31}$

\section{Limitations of the present study}

Our study has important strengths. This analysis was performed in a representative cohort of first MI cases, with an age-distribution and sex-distribution routinely seen in clinical practice. Thus, the actual performance of current guidelines on CVD prevention is provided. However, some potential limitations need to be addressed. A 'reality check' of primary prevention guidelines requires that predictors for a first atherosclerotic event can be assessed after the event. They can with the approach used in this study. First, the strongest predictors of risk (age, sex and smoking) can always be determined after as well as before the event, and the impact of small changes in cholesterol and blood pressure on multifactorial risk assessment is critical only near the risk-based decision threshold. Plasma cholesterol was measured early after admission (within the first $24 \mathrm{~h}$ ), which today is accepted to represent baseline values; ${ }^{32}$ plasma cholesterol was indeed only $5 \%$ lower in the 181 patients in whom a paired pre-MI value was available for comparison. The blood pressure used for estimation of predicted risk was obtained in a stable phase, either before MI ( previous hospitalisation or general practitioner) or after recovery from the acute phase (just before hospital discharge or first visit to the rehabilitation clinic). The mean systolic blood pressure $( \pm \mathrm{SD})$ measured before MI was $139.4( \pm 20.3) \mathrm{mm} \mathrm{Hg}(\mathrm{n}=103)$, after MI $137.1( \pm 19.0) \mathrm{mm} \mathrm{Hg}(\mathrm{n}=293, \mathrm{p}=0.28)$. Only few, CVD-free patients without diabetes used statin before the first MI ( $n=26$, age 40-75), and they were excluded. In patients with a first MI, only the detection rate (sensitivity) of decision thresholds can be determined, not the specificity and risk of overtreatment. However, if a decision threshold captures only a minority of those it was intended to identify, its utility may be questioned. Given that the 2013 ACC/AHA and the 2014 NICE/UK guidelines lowered the threshold for primary prevention with statins based on careful risk-benefit and cost-effectiveness considerations, ${ }^{3} 433$ the appropriateness of the much lower sensitivity of the SCORE-based treatment threshold recommended for use in many high-income European countries $^{1}$ deserves to be reconsidered.

\section{CONCLUSION}

The 2012 ESC and the 2013 ACC/AHA and 2014 NICE/UK guidelines differ substantially in their ability to secure statin therapy to those destined for a first MI. In Europe, with the exception of UK, eligibility for primary prevention with statins is becoming increasingly restricted in non-Eastern European countries by updating only the mortality-based SCORE equations, not the risk thresholds on which treatment decisions are based. In the USA and UK, a treatment threshold based on risk-benefit and cost-effectiveness considerations ${ }^{3} 42433$ has now been defined, leading to a wider eligibility for primary prevention with statin therapy.

Acknowledgements The authors thank Ole May, Ole Gotzsche, Helle Kanstrup, Jette Bertelsen, Helle K Jensen, Willemijn Comuth and Kim Sivesgaard for their assistance in collecting information on traditional risk factors from the medical records.

Contributors MBM and EF contributed equally to this study, including study design, data analysis, interpretation of the results, drafting the manuscript and final approval of the manuscript.

Funding This work was supported by the Institute of Clinical Medicine at Aarhus University, Denmark.

\section{Competing interests None.}

Ethics approval The study was approved by the Danish Data Protection Agency (Reference: 2007-58-0010, int. ref: 1-16-02-46-12). Registry studies do not require ethical approval in Denmark.

Provenance and peer review Not commissioned; externally peer reviewed.

Data sharing statement No additional data are available.

Open Access This is an Open Access article distributed in accordance with the Creative Commons Attribution Non Commercial (CC BY-NC 4.0) license, which permits others to distribute, remix, adapt, build upon this work noncommercially, and license their derivative works on different terms, provided the original work is properly cited and the use is non-commercial. See: http:// creativecommons.org/licenses/by-nc/4.0/

\section{REFERENCES}

1. Perk J, De Backer G, Gohlke H, et al. European Guidelines on cardiovascular disease prevention in clinical practice (version 2012). Eur Heart J 2012;33:1635-701.

2. Goff DC Jr, Lloyd-Jones DM, Bennett G, et al. 2013 ACC/AHA Guideline on the Assessment of Cardiovascular Risk: a report of the American College of Cardiology/American Heart Association Task Force on Practice Guidelines. Circulation 2014;129(25 Suppl 2): S49-73.

3. Stone NJ, Robinson J, Lichtenstein AH, et al. $2013 \mathrm{ACC} / \mathrm{AHA}$ Guideline on the Treatment of Blood Cholesterol to Reduce Atherosclerotic Cardiovascular Risk in Adults: a report of the American College of Cardiology/American Heart Association Task Force on Practice Guidelines. Circulation 2014;129(25 Suppl 2):S1-45. 
4. National Institute for Health and Care Excellence (NICE) Clinical Guideline CG181: Lipid modification-Cardiovascular risk assessment and the modification of blood lipids for the primary and secondary prevention of cardiovascular disease. National Clinical Guideline Centre, July 2014. http://www.nice.org.uk/Guidance/cg181 (accessed 26 July 2014).

5. JBS3 Board. Joint British Societies' consensus recommendations for the prevention of cardiovascular disease (JBS3). Heart 2014;100 (Suppl 2):ii1-67.

6. Thygesen K, Alpert JS, White HD; Joint ESC/ACCF/AHA/WHF Task Force for the Redefinition of Myocardial Infarction. Universal definition of myocardial infarction. Eur Heart J 2007;28:2525-38.

7. Mortensen MB, Sivesgaard K, Jensen HK, et al. Traditional SCORE-based health check fails to identify individuals who develop acute myocardial infarction. Dan Med J 2013;60:A4629.

8. National Cholesterol Education Program (NCEP) Expert Panel on Detection, Evaluation, and Treatment of High Blood Cholesterol in Adults (Adult Treatment Panel III). Third Report of the NCEP Expert Panel on Detection, Evaluation, and Treatment of High Blood Cholesterol in Adults final report. Circulation 2002;106:3143-421.

9. Grundy SM, Cleeman JI, Merz CN, et al. Implications of recent clinical trials for the National Cholesterol Education Program Adult Treatment Panel III guidelines. Circulation 2004;110:227-39.

10. Conroy RM, Pyörälä K, Fitzgerald AP, et al. Estimation of ten-year risk of fatal cardiovascular disease in Europe: the SCORE project. Eur Heart J 2003;24:987-1003.

11. Dawber TR, Kannel WB, Lyell LP. An approach to longitudinal studies in a community: the Framingham study. Ann N Y Acad Sci 1963;107:539-56.

12. Kannel WB, Feinleib M, McNamara PM, et al. An investigation of coronary heart disease in families. The Framingham offspring study. Am J Epidemiol 1979;110:281-90.

13. Friedman GD, Cutter GR, Donahue RP, et al. CARDIA: study design, recruitment, and some characteristics of the examined subjects. J Clin Epidemiol 1988;41:1105-16.

14. Investigators TA. The Atherosclerosis risk in communities (ARIC) study: design and objectives. Am J Epidemiol 1989;129:687-702.

15. Fried LP, Borhani NO, Enright $P$, et al. The Cardiovascular Health Study: design and rationale. Ann Epidemiol 1991;1:263-76.

16. Hippisley-Cox J, Coupland C, Vinogradova Y, et al. Predicting cardiovascular risk in England and Wales: prospective derivation and validation of QRISK2. BMJ 2008;336:1475-82.

17. ESC HeartScore risk calculator. http://www.heartscore.org (accessed 27 May 2014).
18. Cooney MT, Dudina AL, Graham IM. Value and limitations of existing scores for the assessment of cardiovascular risk: a review for clinicians. J Am Coll Cardiol 2009;54:1209-27.

19. Lloyd-Jones DM. Cardiovascular risk prediction: basic concepts, current status, and future directions. Circulation 2010;121:1768-77.

20. Ray KK, Kastelein JJ, Boekholdt SM, et al. The ACC/AHA 2013 guideline on the treatment of blood cholesterol to reduce atherosclerotic cardiovascular disease risk in adults: the good the bad and the uncertain: a comparison with ESC/EAS guidelines for the management of dyslipidaemias 2011. Eur Heart $J$ 2014;35:960-8.

21. Lloyd-Jones DM, Goff D, Stone NJ. Statins, risk assessment, and the new American prevention guidelines. Lancet 2014;383:600-2.

22. Robinson JG. Accumulating evidence for statins in primary prevention. JAMA 2013;310:2405-6.

23. loannidis JP. More than a billion people taking statins?-potential implications of the new cardiovascular guidelines. JAMA 2014;311:463-4.

24. Deaño RC, Pandya A, Jones EC, et al. A look at statin cost-effectiveness in view of the 2013 ACC/AHA cholesterol management guidelines. Curr Atheroscler Rep 2014;16:438.

25. Pencina MJ, Navar-Boggan AM, D'Agostino RB Sr, et al. Application of new cholesterol guidelines to a population-based sample. $N$ Engl J Med 2014;370:1422-31.

26. Kavousi M, Leening MJ, Nanchen D, et al. Comparison of application of the ACC/AHA guidelines, Adult Treatment Panel III guidelines, and European Society of Cardiology guidelines for cardiovascular disease prevention in a European cohort. JAMA 2014;311:1416-23.

27. Jackson R, Kerr A, Wells $S$. Vascular risk calculators: essential but flawed clinical tools? Circulation 2013;127:1929-31.

28. Ridker PM, Cook NR. Statins: new American guidelines for prevention of cardiovascular disease. Lancet 2013;382:1762-5.

29. Capewell S, O'Flaherty M. Rapid mortality falls after risk-factor changes in populations. Lancet 2011;378:752-3.

30. Muntner P, Colantonio LD, Cushman M, et al. Validation of the atherosclerotic cardiovascular disease pooled cohort risk equations. JAMA 2014;311:1406-15.

31. Ridker PM, Danielson E, Fonseca F, et al. JUPITER Study Group. Rosuvastatin to prevent vascular events in men and women with elevated C-reactive protein. $N$ Engl J Med 2008;359:2195-207.

32. Pitt B, Loscalzo J, Ycas J, et al. Lipid levels after acute coronary syndromes. J Am Coll Cardiol 2008;51:1440-5.

33. Hawkes N. NICE sticks to its advice to drop threshold for prescribing statins. BMJ 2014;349:g4694. 